\title{
Peran Orangtua Dan Guru Pak Dalam Pembentukan Karakter Rohani Anak Di Sdn Cawang 01 Pagi, Jakarta Timur
}

\author{
Juni Wando Purba \\ Institut Agama Kristen Negeri Ambon \\ juniwando92@gmail.com
}

\begin{abstract}
The study aims to describe the role of PAK's parents and teachers in the formation of children's spiritual characters. The focus of this research is how PAK's parent and teacher roles are in the formation of child's spiritual character. Research was conducted at SDN Cawang 01 Pagi and as a source of data for children's parents, Guru PAK, and a Christian child. Data collection techniques consist of literature reviews, interviews, and documentation. The instruments in this research are interview guidelines, and are denomented. The data analysis technique used in this study is a qualitative data analysis, following the concepts given Miles and Huberman and Spradley. From the results of the analysis of data obtained the conclusion of the parent role in the formation of children's spiritual character in the school Cawang 01 morning, not entirely fulfilled. While the role of teachers PAK SDN Cawang 01 Pagi, has been done with the maximum, namely as educators, counselors, advisers, motivators, evangelists, communicators, and socialization agents and roles in accordance with the demands of the curriculum KTSP.
\end{abstract}

Keyword: parents, master teacher, spiritual character

\section{Pengantar}

Akar dari semua tindakan kejahatan, terletak pada hilangnya karakter. Menurut John Yates dan Alexander Yates karakter adalah kualitas dasar dari sesuatu, esensi dari apa yang menyusun seseorang. Selanjutnya, Menurut Widyapranawa (2008) karakter adalah penyatuan seluruh ekspresi yang harmonis dari akal-budi, perasaan, dan tubuh.

Dengan demikian karakter dimaknai sebagi cara berfikir dan berperilaku yang khas tiap individu untuk hidup dan bekerja sama, baik dalam lingkup keluarga, masyarakat, bangsa dan Negara. Individu yang berkarakter baik adalah individu yang dapat membuat keputusan dan siap mempertanggungjawabkan setiap akibat dari keputusannya. Karakter dapat dianggap sebagi nilainilai perilaku manusia yang berhubungan dengan Tuhan Yang Maha Esa, diri sendiri, sesama manusia, lingkungan, dan kebangsaan yang terwujud dalam pikiran, sikap, perasaan perkataan dan perbuatan berdasarkan norma-norma agama.

Menurut penulis setiap orang percaya kepada Yesus Kristus memiliki karakter rohani yang dapat diwujudkan dalam kehidupan sehari-hari. Adapun ciri-ciri orang yang memiliki karakter rohani, yaitu: (1) memiliki iman yang teguh kepada Tuhan; (2) rajin beribadah; (3) rajin berdoa; (4) memiliki pengharapan kepada Tuhan; (5) bersyukur atas pemberian Tuhan; (6) menghormati orangtua; (7) jujur; (8) disiplin; (9) memiliki simpati dan empati; (10) sukacita; (11) kasih. Karakter tersebut dibentuk dalam keluarga dan lingkungan sekolah.
Kehidupan keluarga adalah persiapan bagi kehidupan di masyarakat. Kesejahteraan masyarakat untuk sebagian besar bergantung dari pendidikan yang diterima oleh anak di dalam keluarga.

Karakter rohani anak sebagaimana penulis tulis di atas merupakan harapan dari setiap orangtua dan guru PAK. Tetapi yang sering terjadi harapan itu tidak tercapai karena anak lebih cenderung mewujudkan karakter yang tidak baik di keluarga maupun di sekolah. Dalam keluarga anak lebih cenderung melawan orangtua, tidak mendengarkan nasihat orangtua, membantu orangtua dengan rasa terpaksa, kurangnya sopan santun, dan lain-lain. Di sekolah anak cenderung bersikap kurang sopan santun kepada guru, dalam berteman membalas kejahatan dengan kejahatan, tutur kata tidak baik, suka marah, tidak mengerjakan PR dengan serius, dan lain-lain.

Mengingat masalah di atas penulis mengangkat judul Peran Orangtua dan Guru PAK Dalam Pembentukan Karakter Rohani Anak di SDN Cawang 01 Pagi.

\section{Tinjauan Literatur \\ Peran Orangtua}

Peran orangtua dalam pembentukan karakter rohani anak sudah ada sejak zaman Perjanjian Lama. Hal ini dapat dilihat dalam Ulangan 11:2, 5 dikatakan "Kamu tahu sekarang kukatakan bukan kepada anak-anakmu, yang tidak mengenal dan tidak melihat hajaran Tuhan, Allahmu-kebesaranNya, tangan-Nya yang kuat dan lengan-Nya yang 
teracung ... apa yang dilakukan-Nya terhadapmu di padang gurun, sampai kamu tiba di tempat ini". Firman ini menyiratkan dilema dari proses pembentukan karakter rohani anak. Apa yang diketahui oleh sebuah generasi melalui pengalaman pribadi dengan Allah harus dikomunikasikan kepada generasi baru yang tidak memiliki pengalaman itu. Akan tetapi iman harus dikomunikasikan, karena melalui iman, karakter rohani anak semakin baik misalnya, saling mengasihi sesama tanpa membedabedakan dan menghormati orangtua.

Perjanjian Baru peran orangtua juga ditekankan sebagai pendidik terhadap anak-anaknya. Dalam Efesus 6:4 dikatakan bahwa "Dan kamu bapa-bapa janganlah bangkitkan amarah di dalam hati anak-anakmu, tetapi didiklah mereka di dalam ajaran dan nasihat Tuhan". Setiap perkataan dan perbuatan dari setiap orangtua akan menjadi firman yang hidup pada diri setiap anaknya.

Berbicara mengenai orangtua sebagai pendidik yang utama dalam diri anak. Tentu harus memahami dan melaksanakan peran dalam setiap perkembangan anak. Adapun peran orangtua, yaitu: (1) sebagai orangtua, mereka membesarkan, merawat, memelihara, dan memberikan anak kesempatan berkembang. (2) orangtua sebagai guru terhadap anak di keluarga ia mengajarkan ketangkasan motorik, keterampilan melalui latihanlatihan, mengajarkan peraturan-peraturan, tata cara keluarga, tatanan lingkungan masyarakat, menanamkan pedoman hidup bermasyarakat. (3) sebagai tokoh teladan, orangtua menjadi tokoh yang ditiru pola tingkahlakunya, cara berekspresi, cara berbicara. (4) sebagai pengawas, orangtua memperhatikan, mengamati kelakuan, tingkah laku anak. Mereka mengawasi anak agar tidak melanggar peraturan di rumah maupun di luar lingkungan keluarga (Singgih, 2002)

\section{Peran Guru PAK}

Sekolah sebagai pembentukan karakter merupakan lingkungan tempat anak dibimbing, dididik dan dilatih dari setiap generasi supaya mengetahui tentang apa yang diharapkan dan dituntut suatu kebudayaan sekitarnya (Cully, 2012) Untuk mencapai aktivitas tersebut maka menurut Sidjabat (2014) guru PAK tidak hanya melaksanakan peran sebagai pendidik melainkan memiliki banyak peran, yaitu: pengajar, pelatih, fasilitator, motivator, pemimpin, komunikator, agen sosialisasi, pembimbing, imam dan sebagai penginjil. Tuntutan ini juga yang menjadi salah satu tujuan PAK, yaitu membimbing murid dalam cara menggunakan kebenaran-kebenaran asasi Alkitab itu untuk keselamatan seluruh hidupnya. Kebenaran tersebut menjadi fondasi yang utama dalam diri anak dalam menumbuhkembangkan karakter rohani supaya lebih baik dan anugrah Allah yang menyelamatkan seluruh hidupnya.

Dalam lingkungan sekolah jika dilihat dari segi kebutuhan anak, guru terpanggil memainkan sejumlah peran individual dan sosial supaya anak mampu mengendalikan dirinya sendiri dan berinteraksi dengan masyarakatnya dengan baik. Dalam hal ini benarlah bahwa peran guru bukan hanya menjelaskan bahan pengajaran saja tetapi juga melatih dan membimbing anak supaya hidup sebagai anak yang mandiri dan bersosial (Sidjabat, 2014).

Mengingat tanggung jawab guru PAK sebagai pembentukan karakter rohani anak, maka guru PAK harus memiliki sifat yang baik sehingga anak merasa nyaman dan bahagia bersamanya. Sifat yang amat menarik tersebut sampai sekarang masih memberikan dampak yang baik bagi pendidikan anak misalnya ia hendaknya mempunyai sikap keibu-bapaan terhadap anak dan memandang dirinya sebagai wakil orangtua. Sikap keibu-bapaan disini bahwa ia benar-benar memberikan kasih yang benar-benar tulus tanpa memandang latar belakang anak yang ada bersamanya dan peka terhadap kebutuhan anak. Kasih yang tulus akan memberikan karakter rohani anak yang sangat baik. Karena anak akan mengasihi sesamanya dan Allah seperti guru PAK yang telah mengasihinya, ia tidak akan membeda-bedakan temannya. Dengan demikian guru PAK harus mencontoh teladan Tuhan Yesus dalam segala hal (Boehlke, 2011).

\section{Karakter Rohani}

Karakter rohani merupakan seluruh kualitas positif dari sifat-sifat kejiwaan, akhlak, atau budi pekerti, dan kompleksitas mental yang dikuasai oleh Roh Kudus dalam diri anak yang memampukannya bersikap dan bertingkah sesuai dengan ajaran Tuhan Yesus.

\section{Faktor-faktor Pembentukan Karakter}

Stephen Tong (2014) menyebutkan ada beberapa faktor-faktor pembentuk karakter:

1. Kebenaran

Kebenaran bagi orang Kristen adalah dasar dan prinsip, rencana dan perintah-perintah Alkitab, yang terwujud di dalam diri Yesus Kristus dan pengajaran-Nya. Sebagai orang Kristen bukan sekedar belajar firman Tuhan sebagai 
PERAN ORANGTUA DAN GURU PAK DALAM PEMBENTUKAN KARAKTER ROHANI ANAK DI SDN CAWANG 01 PAGI, JAKARTA TIMUR

pengetahuan, tetapi harus menerapkan dan hidup secara keseluruhan berdasarkan pada kebenaran firman.

2. Agama

Fungsi agama dalam pembentukan karakter sebagai pengontrol dan menguasai kepribadian. Agama baik untuk menjaga dan menghentikan berkembangnya dan merajalelanya kejahatan secara berlebihan.

3. Kesengsaraan

Kesengsaraan-kesengsaraan atau kepahitankepahitan mengukir, melatih, meneguhkan, tetapi sekaligus membahayakan suatu kepribadian. Kesengsaraan dan kepahitan membentuk pribadi seseorang, dan memberikan akibat kepada keputusan-keputusan yang akan pribadi itu ambil bagi pribadi itu sendiri.

4. Roh Kudus

Tuhan Allah mengajar dengan mengirimkan Roh Kudus sebagaimana tertulis dalam Yohanes 14:16-17, 26; 16:13 “Aku akan meninggalkan kamu, tetapi aku akan minta kepada Bapa supaya Ia mengirimkan Roh Kudus kepada kamu, dan kalau Roh Kudus itu datang, ia akan mengajarmu dan memimpinmu masuk ke dalam seluruh kebenaran." Ini membuktikan bahwa Yesus tidak menyertai murid-murid-Nya secara fisik terusmenerus tetapi menyerahkan murid-murid-Nya kepada Roh Kudus dalam membimbing mereka mendapatkan kebenaran yang sejati dan bisa hidup di dalamnya.

\section{Metode}

Metode yang digunakan dalam penelitian ini, yaitu metode kualitatif. Bodgan dan Taylor dalam (Bosrowi \& Suwandi, 2008) mendefinisikan metodologi kualitatif sebagai prosedur penelitian yang menghasilkan data deskriptif berupa kata-kata tertulis atau lisan dari orang-orang dan perilaku yang dapat diamati. David Wiliams dalam (Moleong, 2012) menulis bahwa penelitian kualitatif adalah pengumpulan data pada suatu sumber latar alamiah, dengan menggunakan metode alamiah, dan dilakukan oleh orang atau peneliti yang tertarik secara alamiah. Denzim dan Lincon dalam (Moleong, 2012) menyatakan bahwa penelitian kualitatif adalah penelitian yang menggunakan latar alamiah, dengan maksud menafsirkan fenomena yang terjadi dan dilakukan dengan jalan melibatkan berbagai metode yang ada. Kirk dan Miller dalam (Moleong, 2012) mendefinisikan bahwa penelitian kualitatif adalah tradisi tertentu dalam ilmu pengetahuan sosial yang secara fundamental bergantung dari pengamatan pada manusia baik dalam kawasannya maupun dalam peristilahannya.

Teknik pengumpulan data yang penulis lakukan, yaitu: tinjauan literatur, wawancara, dan dokumentasi.

Populasi yang akan diwawancarai yaitu orangtua anak yang berjumlah 48 orang; guru PAK berjumlah 1 orang, dan 48 anak. Adapun alasan penulis menyebutkan 48 orangtua, karena orangtua anak hanya satu selalu berada di rumah. Teknik sampling yang penulis lakukan, yaitu dengan menggunakan purposive sampling, karena untuk menentukan sesorang menjadi sampel didasarkan pada tujuan tertentu (Sugiyono, 2010).

Teknik analisis data yang digunakan dalam penelitian ini adalah analisis data kualitatif, mengikuti konsep yang diberikan Miles and Huberman and Spradley.

Miles and Huberman dalam (Moleong, 2012), mengemukakan bahwa aktivitas dalam analisis data kualitatif dilakukan secara interaktif dan berlangsung secara terus menerus sampai tuntas, sehingga datanya sudah jenuh. Aktivitas dalam analisis data, yaitu data reduction, data display, dan data conclusion drawing/verification.

Selanjutnya menurut Spradley, teknik analisis data disesuaikan dengan tahapan dalam penelitian. Pada tahap penjelajahan dengan teknik data ground tour questions, analisis data dilakukan dengan analisis domain. Pada tahap menentukan fokus analisis data dilakukan dengan anlisis taksonomi. Pada tahap selection, analisis data dilakukan dengan analisis kompenensial. Untuk sampai menghasilkan judul dilakukan dengan analisis tema. Analisis data Miles dan Huberman, yang meliputi data reduction, data display, dan verification dilakukan pada setiap tahapan penelitian menurut Spradley, (penjelajahan, fokus, dan selection).

\section{Hasil dan Pembahasan}

SDN Cawang 01 Pagi. SDN tersebut berlokasi di Provinsi DKI Jakarta, Kabupaten Kota Jakarta Timur, Kecamatan Kramat Jati, Kelurahan Cawang, RT. 01 / RW. 03, Jln. Dewi Sartika No. 200, Kode pos13630, Kode NPSN 20104383, Telepon: (021) 8017231. Bangunan sekolah memiliki halaman yang cukup luas. Gedung yang dimiliki SDN Cawang 01 Pagi terdiri dari 21 ruang kelas, 1 ruang kepala sekolah, 1 ruang operator, 1 ruang kantor guru, 1 
ruang UKS, 1 ruang Perpustakan, 1 ruang lab. IPA. Jumlah siswa SDN Cawang 01 pada tahun ajaran 2016/2017 berjumlah 692, dengan perincian siswa yang beragama Islam 644 sedangkan Kristen 48.

\section{Wawancara Kepada Orangtua Definisi karakter rohani dan ciri-ciri anak yang memiliki karakter rohani}

Karakter rohani merupakan seluruh kualitas positif dari sifat-sifat kejiwaan, akhlak, atau budi pekerti, dan kompleksitas mental yang dikuasai oleh Roh Kudus dalam diri anak yang memampukannya bersikap dan bertingkah sesuai dengan ajaran Tuhan Yesus.

Ciri-ciri anak yang memiliki karakter rohani ia mampu mewujudkan sikap percaya kepada Tuhan, menghormati orangtua, rajin membaca Alkitab, rajin berdoa, mengasihi sesama, menolong sesama, memiliki pengharapan kepada Tuhan, dan rajin beribadah, rajin berdoa, bersyukur atas pemberian Tuhan, menghormati orangtua, bersikap jujur, dan menunjukkan sikap belas kasihan.

Dari keseluruhan pernyataan orangtua, penulis melihat ada beberapa karakter yang kadang-kadang dilakukan anak-anak seperti: rajin beribadah, bersikap jujur, dan menolong sesama. Menurut informan anak-anak rajin beribadah ketika mereka memiliki teman yang dikenalnya dengan baik sedangkan apabila anak-anak belum memiliki teman ia cenderung kurang bersemangat mengikuti ibadah. Selain faktor teman, orangtua juga kurang dalam membimbing dan mengarahkan anak rajin beribadah hal ini dapat dilihat ketika anak lebih memilih aktifitas lain daripada mengikuti ibadah. Dalam bersikap jujur masih ada anak-anak yang tidak jujur kepada orangtua seperti ketika mendapat nilai rendah dari sekolah anak-anak takut menyampaikannya kepada orangtua karena takut dimarahi karena mendapat nilai rendah. Sikap tolong-menolong tidak selalu diwujudkan anak-anak seperti yang diajarkan Tuhan, melainkan cenderung menolong teman yang pernah menolongnya saja.

\section{Pemahaman tentang peran orangtua dalam pembentukan karakter rohani anak}

Peran orangtua yaitu perangkat tingkah yang diharapkan dan dimiliki oleh ayah dan ibu kandung yang sifatnya sesuai dengan ajaran Tuhan dalam pembentukan karakter rohani anak. Adapun peran orangtua dalam pembentukan karakter rohani anak, yaitu sebagai pendidik, pembimbing, motivator, dan sebagai teladan.
Informan menjelaskan pembentukan karakter rohani anak dimulai dari teladan dari setiap orangtua kemudian cara pengajaran dilaksanakan secara terus-menerus seperti melatih anak memahami dan melaksanakan kesepuluh firman Tuhan, menasihati anak supaya selalu berbuat baik, mengajarakan anak rajin membaca Alkitab, melibatkan anak dalam aktifitas gereja, mengajarkan anak rajin berdoa, mengajarkan dan melatih anak berbicara yang sopan. Dalam pelaksanaannya dalam keluarga peran tersebut dilaksanakan oleh ayah dan ibu secara bersama. Berdasarkan wawancara dengan informan yang lebih sering melaksanakan peran tersebut adalah ibu karena ayah lebih lama bekerja mencari kebutuhan keluarga di luar rumah

Adapun cara yang dilakukan orangtua dalam pembentukan karakter anak mengajarkan firman Allah dan melatih anak berperilaku yang sesuai dengan ajaran Tuhan. Proses pengajaran ini dilakukan orangtua sejak anak bayi anak-anak dibawa ke gereja, mengajarkan kejujuran, mengajarkan menghormati orangtua dan yang paling utama mengasihi Allah dengan rajin beribadah, rajin berdoa, rajin membaca Alkitab dan melakukan firman Tuhan dalam kehidupan sehari-hari. Media yang selalu dipakai orangtua dalam mengajarkan firman Tuhan yaitu Alkitab, video tokoh-tokoh Alkitab, dan menyediakan buku-buku rohani untuk bacaan anak-anak.

\section{Tantangan dan kesulitan dalam pembentukan karakter rohani anak}

Dalam pembentukan karakter rohani anak, tantangan dan kesulitan yang sering dialami orangtua seperti lingkungan dan kurangnya peran orangtua dalam membimbing anak. berdasarkan hasil wawancara dengan orangtua, lingkungan tempat anak bermain lebih sering memberikan pengajaran yang kurang baik kepada anak-anak. Mengenai peran orangtua sebagai pembimbing, penulis mengamati kurangnya waktu orangtua bersama anak dalam keluarga sehingga anak berperilaku tidak sesuai dengan ajaran Tuhan Yesus, seperti: berbohong, melawan orangtua, dan tutur katanya tidak baik.

Melihat adanya tantangan dan kesulitan yang dihadapi orangtua dalam pembentukan karakter rohani anak penulis memahami perlunya dampingan guru PAK di sekolah dan peran warga gereja terhadap anak-anak dalam pembentukan karakter rohani. 
PERAN ORANGTUA DAN GURU PAK DALAM PEMBENTUKAN KARAKTER ROHANI ANAK DI SDN CAWANG 01 PAGI, JAKARTA TIMUR

Wawancara Kepada guru PAK Definisi karakter rohani dan ciri-ciri anak yang memiliki karakter rohani

Karakter rohani merupakan seluruh kualitas positif dari sifat-sifat kejiwaan, akhlak, atau budi pekerti, dan kompleksitas mental yang dikuasai oleh Roh Kudus dalam diri anak yang memampukannya bersikap dan bertingkah sesuai dengan ajaran Tuhan Yesus.

Ciri-ciri anak yang memiliki karakter rohani ia mampu mewujudkan sikap percaya kepada Tuhan, menghormati orangtua, rajin membaca Alkitab, rajin berdoa, mengasihi sesama, menolong sesama, memiliki pengharapan kepada Tuhan, dan rajin beribadah, rajin berdoa, bersyukur atas pemberian Tuhan, menghormati orangtua, bersikap jujur, dan menunjukkan sikap belas kasihan.

Berdasarkan hasil wawancara kepada guru PAK, penulis melihat anak-anak belum mengasihi sesama dengan ikhlas. Anak-anak lebih sering mengasihi teman-temannya yang lebih dahulu mengasihinya, dalam berteman anak-anak lebih sering pilih kasih yang mengakibatkan adanya kelompok-kelompok diantara mereka. Melihat adanya sikap pilih kasih pada anak, guru PAK mengajarkan kepada setiap anak supaya jangan melakukan sikap tersebut karena tidak sesuai dengan ajaran Tuhan. Cara yang dilakukan guru PAK agar anak mampu menerima perbedaan yang ada diantara mereka seperti mengajarkan anak menerima pendapat temantemannya dan mengajarakan anak supaya mau mengutarakan pendapatnya masing-masing.

\section{Pemahaman tentang peran guru PAK dalam pembentukan karakter rohani anak}

Peran guru PAK ialah sebagai pendidik yang bertujuan mendidik semua anak agar mereka terlibat dalam penelaahan Alkitab secara cerdas sebagaimana dengan bimbingan Roh Kudus, melatih anak mengambil bagian dalam kebaktian dan memperlengkapinya untuk memilih cara-cara mengejawantahkan pengabdian diri kepada Allah Bapa dan Yesus Kristus dalam pekerjaan sehari-hari serta hidup bertanggung jawab di bawah kedaulatan Allah dan kemuliaan-Nya sebagai lambang ucapan syukur mereka yang dipilih dalam Yesus Kristus.

Guru PAK dalam lingkungan sekolah merupakan orangtua kedua bagi anak yang melanjutkan dan mengembangkan pembentukan karakter rohani anak yang telah diperoleh dalam keluarga. Berdasarkan hasil wawancara kepada informan, penulis melihat peran guru PAK sebagai pendidik, konselor, pembimbing, motivator, penginjil, komunikator, dan agen sosialisasi dalam pembentukan karakter rohani anak sudah terlaksana.

Guru PAK sebagai pendidik. Informan mengatakan dalam hal ini selalu mengajarkan kepada anak-anak sikap dan perilaku yang sesuai dengan ajaran Tuhan. Adapun cara guru PAK dalam mendidik anak seperti melibatkan anak-anak dalam pembacaan firman Tuhan, menjelaskan makna dari ayat alkitab, dan merefleksikan setiap materi yang telah dipelajari kepada anak. Guru PAK sebagai konselor selalu memberikan waktu untuk mendengar kegelisahan dan persoalan anak, lalu bersama-sama mencari upaya upaya mengatasinya dalam terang firman Tuhan serta pertolongan Roh Kudus. Dalam melaksanakan peran sebagai pembimbing, guru PAK terlebih dahulu mengetahui dengan jelas setiap pergumulan yang ada pada anak dan membimbing anak keluar dari pergumulannya.

\section{Simpulan}

Berdasarkan hasil tinjaun literatur dan hasil penelitian yang telah penulis paparkan, maka penulis menyimpulkan secara teoretis dan praktik, sebagai berikut:

1. Karakter rohani merupakan seluruh kualitas positif dari sifat-sifat kejiwaan, akhlak, atau budi pekerti, dan kompleksitas mental yang dikuasai oleh Roh Kudus dalam diri anak yang memampukannya bersikap dan bertingkah sesuai dengan ajaran Tuhan Yesus. Adapun ciri-ciri anak yang memiliki karakter rohani, yaitu: ia mampu mewujudkan sikap percaya kepada Tuhan, menghormati orangtua, rajin membaca Alkitab, rajin berdoa, mengasihi sesama, menolong sesama, memiliki pengharapan kepada Tuhan, dan rajin beribadah, rajin berdoa, bersyukur atas pemberian Tuhan, menghormati orangtua, bersikap jujur, dan menunjukkan sikap belas kasihan.

2. Peran orangtua dalam pembentukan karakter rohani anak, yaitu: sebagai pendidik, sebagai guru, sebagai tokoh teladan, dan sebagai pengawas.

3. Peran guru PAK dalam pembentukan karakter rohani anak, yaitu: sebagai pendidik, konselor, pembimbing, motivator, penginjil, komunikator, dan agen sosialisasi. Dalam mendidik anak-anak, guru PAK menguraikan dan menerangkan kepercayaan Kristen, karena 
itu ia harus menyampaikan harta-harta masa lampau kepada anak-anak yang akan menempuh masa depan. Ia membentangkan dihadapan anak-anak segala kekayaan pernyataan Allah dalam Yesus Kristus sebagaimana tersimpan dalam Alkitab. Sebagai konselor, guru PAK memberikan waktu untuk mendengar kegelisahan dan persoalan anak, lalu bersama-sama mencari upaya mengatasinya dalam terang firman Tuhan serta pertolongan Roh Kudus. Sebagai pembimbing, guru PAK terlebih dahulu mengenal anak-anak dengan jelas setelah itu ia membimbing anakanak ke dalam terang Allah. Sebagai motivator, guru PAK menunjukkan antusiasme terhadap pengajaran yang disampaikannnya serta mendemonstrasikan itikad baik untuk membina relasi yang membangun dengan anak-anak. Sebagai penginjil, guru PAK menjelaskan injil dan mengenalkan kepada anak bahwa Yesus Kristus sebagai juruselamatnya dengan pertolongan Roh Kudus. Sebagai komunikator, guru PAK menyampaikan informasi yang berguna bagi anak-anak dan menegur anak ketika berbuat yang tidak sesuai dengan ajaran Tuhan. Sebagai agen sosialisasi, guru PAK membangun interaksi edukatif yang menyenangkan, yang di dalamnya anak-anak saling mengenal dan saling mengisi.

4. Peran orangtua dalam pembentukan karakter rohani anak-anak yang sekolah di SDN Cawang 01 Pagi dan peran guru PAK SDN Cawang 01 Pagi, sebagai berikut:

1. Peran orangtua dalam membentuk karakter rohani anak-anak yang sekolah di SDN Cawang 01 Pagi, belum seluruhnya terlaksana. Hal ini disebabkan kurangnya waktu orangtua bersama anak, kurangnya perhatian orangtua terhadap pembentukan karakter rohani anak, dan orangtua lebih memenuhi keinginan anak, kurang dalam menjalin komunikasi terhadap guru PAK tentang perkembangan karakter rohani anak-anak. Peran orangtua yang telah terlaksana hanya sebagai pencari nafkah.

2. Sedangkan peran Guru PAK dalam pembentukan karakter rohani anak di SDN Cawang 01 Pagi, sudah terlaksana dengan maksimal hal ini dapat dilihat dari peran guru PAK dalam membentuk karakter rohani anak seperti: sebagai pendidik, konselor, pembimbing, motivator, penginjil, komunikator, dan agen sosialisasi dan peran tersebutlah yang dituntut kurikulum yang digunakan.

\section{Saran Dan Rekomendasi}

Berdasarkan pembahasan yang telah penulis paparkan, maka penulis memberikan saran bagi beberapa pihak, yaitu:

\section{SDN Cawang 01 Pagi}

1. Menyusun kegiatan-kegiatan yang mendidik dan membentuk anak-anak berperilaku sesuai dengan ajaran Tuhan. Tujuannya agar anakanak memiliki persiapan yang matang dalam melayani Tuhan sesuai dengan talenta yang mereka miliki.

2. Melibatkan anak-anak dalam kegiatan kerohanian di sekolah. Tujuannya agar anakanak semakin bertumbuh sesuai dengan ajaran Tuhan.

3. Menasihati anak ketika berperilaku tidak sesuai dengan ajaran Tuhan. Tujuannya agar anakanak mengetahui perilaku yang sesuai dengan ajaran Tuhan.

4. Kepala sekolah dan guru-guru bersama-sama ikut serta mendidik dan membimbing anak berperilaku baik. Tujuannya agar seluruh pendidik di SDN Cawang 01 bersama membentuk karakter yang baik dalam diri anak

5. Menerapkan kurikulum 2013.

Agar seluruh kegiatan sekolah menumbuhkembangkan ranah kognitif, afektif, dan psikomotor anak secara seimbang.

\section{Orangtua anak-anak}

1. Mengajarkan anak-anak berperilaku sesuai dengan kehendak Tuhan. Tujuannya agar anakanak mampu mewujudkan perilaku yang sesuai dengan ajaran Tuhan dalam kehidupan seharihari.

2. Memberikan waktu bersama anak.

Tujuannya agar orangtua semakin mengetahui perkembangan karakter rohani anak dan anakanak mengenal mampu mengasihi sesama seperti mengasihi dirinya sendiri.

3. Ayah dan Ibu bersama-sama dalam pembentukan karakter rohani anak.

Tujuannya agar ayah dan ibu bersama melaksanakan perannya dalam pembentukan karakter rohani anak, sebab pembentukan karakter rohani pertama di dalam keluarga.

4. Menerima kelebihan dan kekurangan anakanak. 
PERAN ORANGTUA DAN GURU PAK DALAM PEMBENTUKAN KARAKTER ROHANI ANAK DI SDN CAWANG 01 PAGI, JAKARTA TIMUR

Tujuannya agar anak-anak mampu menerima kelebihan dan kelemahan oralnglain tanpa membeda-bedakannya sebagaimana orangtua telah menerima mereka dengan penuh kasih sayang.

5. Membangun komunikasi dengan guru PAK khususnya dalam pembentukan karakter rohani anak. Tujuannya agar orangtua dan guru PAK bersama melaksanakan perannya dalam pembentukan karakter rohani anak.

\section{Guru PAK di SDN Cawang 01 Pagi}

1. Selalu melaksanakan perannya dalam pembentukan karakter rohani anak.

Tujuannya agar anak-anak memiliki karakter rohani dan mewujudkannya dalam kehidupan sehari-hari.

2. Melibatkan anak dalam pembacaan Alkitab. Tujuannya agar anak-anak mengenal Allah, mengetahui kemahakuasaan Allah, dan mengetahui ajaran Tuhan.

3. Melibatkan anak dalam ibadah sebelum dan sesudah pelajaran. Tujuannya agar anak-anak mampu melayani Allah dengan talenta yang dimilikinya.

4. Mengajarkan anak melakukan perintah Tuhan. Tujuannya agar anak-anak tidak hanya mengetahui firman Tuhan saja melainkan mampu mewujudkannya dalam kehidupan sehari-hari.

\section{Ucapan Terima Kasih}

Pada Kesempatan ini penulis mengucapkan terima kasih kepada Sdn Cawak 01 Jakarta Timur, yang telah bersedia untuk menjadi tempat penulis melakukan penelitian. Penulis juga mengucapkan terima kasih kepada redaktur yang telah memberikan masukan yang begitu berharga sehingga tulisan ini dapat disajikan di dalam jurnal Institutio.

\section{Pustaka Acuan}

Alkitab dan Kidung Jemaat. Jakarta: Lembaga Alkitab Indonesia, 2010.

Barth Christoph. Teologi Perjanjian Lama I. Jakarta: BPK Gunung Mulia, 2016.

Boehlke Robert R. Sejarah Perkembangan Pikiran dan Praktek Pendidikan Agama Kristen: Dari Plato Sampai IG. Loyola. Jakarta: BPK Gunung Mulia, 2011.
Sejarah Perkembangan Pikiran dan Praktek Pendidikan Agama Kristen: Dari Yohanes Amos Comenius Sampai Perkembangan PAK di Indonesia, Jakarta: BPK Gunung Mulia, 2010.

Cully Iris V. Dinamika Pendidikan Kristen. Jakarta: BPK Gunung Mulia, 2012.

Edlin Richard J. Hakikat Pendidikan Kristen. Jakarta: BPK Gunung Mulia, 2015.

Henry Matthew. Tafsiran Kitab Amsal. Surabaya: Momentum, 2013.

Homrighausen E.G \& Enklar I.H. Pendidikan Agama Kristen. Jakarta: BPK Gunung Mulia, 2014.

Islamuddin Haryu. Psikologi Pendidikan. Yogyakarta: Pustaka Belajar, 2012.

Kamus Besar Bahasa Indonesia Edisi Ketiga. Jakarta: Balai Pustaka, 2007.

Kesuma Dharma, Triatna Cepi \& Permana H. Johar Pendidikan Karakter: Kajian Teori dan Praktik di Sekolah. Bandung: Remaja Rosda karya, 2012.

Kristianto Paulus Lilik. Prinsip \& Paktik Pendidikan Agama Kristen. Yogyakarta: ANDI, 2006.

Martono Nanang. Metode Penelitian Kuantitatif: Analisis Isi dan Analisi Data Sekunder. Jakarta: Raja Grafindo Persada, 2011.

Milla John Virgil. Peran Keluarga Dalam Pendidikan Agama Kristen Terhadap Pertumbuhan Rohani Anak. YAKI, 2012.

Moleong Lexy J. Metodologi Penelitian Kualitatif. Bandung: Remaja Rosdakarya, 2012.

Pandensolang Welly. Keluarga Kristen Rumah Tuhan: Mengubah Keluarga Anda dari Menang Menjadi Lebih Dari Pemenang. Jakarta: Yayasan Agape Indonesia Press, 2012.

Paterson Robert M. Tafsiran Kitab keluaran. Jakarta: BPK Gunung Mulia, 2006

Sadulloh Uyoh. Pedagogik/Ilmu Pendidik. Bandung: Alfabeta, 2010.

Salahuddin Anas \& Irawanto Alkrienciehie. Pendidikan Karakter: Pendidikan Berbasis Agama \& Budaya Bangsa. Bandung: Pustaka Setia, 2013.

Samani Muchlas \& Hariyanto . Konsep dan Model Pendidikan Karakter. Bandung: Remaja Rosdakarya, 2016.

Setiawani Mary Go. Menerobos Dunia Anak. Bandung: Kalam Hidup, 2000. 
Seymour Jack L. Memetakan Pendidikan Kristiani: Pendekatan- Pendekatan Menuju Pembelajaran Jemaat. Jakarta: BPK Gunung Mulia, 2016.

Shelly Judith Allen. Kebutuhan Rohani Anak: Pedoman Untuk Orangtua, Guru, dan Perawat. Bandung: Kalam Hidup, 1982.

Sidjabat B.S. Mengajar Secara Profesional. Bandung: Kalam Hidup, 2014.

Singgih Yulia. Asas-asas Psikologi Keluarga Idaman. Jakarta: BPK Gunung Mulia, 2002.

Sitanggang Sariaman \&Manullang Rusel. Buku Pegangan Guru Pendidikan Agama Kristen. Jakarta: Egrateia Putra Jaya, 2009.

Sitompul Einar M. Perjalanan Sarat Muatan: Buku 1. Jakarta: UPI STT Jakarta, 2014.

. Perjalanan Semua Mendayung: Buku 2. Jakarta: UPI STT Jakarta, 2014.

Sugiyono. Metode Penelitian Kuantitatif dan Kualitatif dan R \& D. Bandung: ALFABETA, 2010.

Sukardi. Metodologi penelitian pendidikan: Kompetensi dan Praktiknya. Jakarta: Bumi Aksara, 2009.

Suwandi \& Basrowi. Memahami Penelitian Kualitatif. Jakarta: Rineka Cipta, 2008.

Walker D.F. Konkordansi Alkitab. Jakarta: BPK Gunung Mulia, 2015.

Widyapranawa S.H. Pendidikan Kepribadian Diri Sendiri. Yogyakarta: Taman Pustaka Kristen, 2008.

Yates John \& Yates Susan Alexander. Mendidik Anak Untuk Memiliki 8 Karakter Utama. Yogyakarta: ANDI, 2013.

https://ahmadbinhandal.wordpress.com/2014/04/27/periha 1-keunggulan-dan-kelemahan-kurikulum-2013/

http://www.kompasiana.com/marisasnia/perbandingankurikulum-ktsp-2006-dan-kurikulum$2013 \quad 54 \mathrm{f} 98564 \mathrm{a} 3331157628 \mathrm{~b} 48 \mathrm{~d} 7$ 